\title{
Matrix-assisted laser desorption ionization and electrospray ionization combined with Fourier transform ion cyclotron resonance mass spectrometry
}

\author{
Paul O. Staneke and Nico M.M. Nibbering \\ Institute of Mass Spectrometry, University of Amsterdam, Nieuwe Achtergracht 129, 1018 WS \\ Amsterdam, The Netherlands
}

\section{Received October 1996}

\begin{abstract}
During recent years, matrix-assisted laser desorption ionization (MALDI) and electrospray ionization (ESI) are successfully employed to analyze biomolecules and polymers. In combination with Fourier transform ion cyclotron resonance (FT-ICR) mass spectrometry, high mass resolution and mass measurement accuracy can be achieved to enable the determination of molecular weights and structural characterization of biochemical compounds larger than $10 \mathrm{kDa}$.
\end{abstract}

\section{Introduction}

For a long time, efforts to analyze routinely large biomolecules (molecular weights in excess of $10 \mathrm{kDa}$ ) by mass spectrometry were unsuccessful because commonly used ionization techniques, such as electron ionization, chemical ionization, field ionization, field desorption and fast atom bombardment could not produce the (quasi) molecular ions of such compounds. Since the development of MALDI and ESI, mass spectrometry has become a recognized tool in biochemical research.

These two methods reduce the fragmentation of the analytes considerably and are therefore referred to as soft ionization techniques. With MALDI and ESI, mass spectrometry can now be used for the analysis of molecules with molecular weights of hundreds of kilodaltons whereas with the relatively harder ionization techniques the upper mass limit in routine applications was only a few kilodaltons. For a molecular weight determination of large biomolecules free from interferences high resolution is essential. The resolution of the presently available time-of-flight (TOF) mass spectrometers with delayed extraction is impressive (mass resolution of 10,000-15,000 is achieved routinely for peptides in the mass range of 1-6 kDa) [1], but not sufficient for accurate mass measurements of ultra-high molecular weight samples.

This problem can be overcome by coupling MALDI and ESI to FT-ICR to achieve ultra-high mass resolution and to perform consequently accurate mass measurements. The FT-ICR technique also provides the possibility to perform multiple MS experiments for structural characterization of macromolecules. 


\section{Matrix-assisted laser desorption ionization (MALDI)}

Initially laser desorption ionization (LDI) $[1,2]$ has been achieved by illuminating a solid sample with a short intense light pulse. Although this technique generates quasi-molecular ions, the efficiency is low and dependent on many variables. These include the wavelength and power density of the laser radiation, the optical absorption characteristics of the sample, the thickness of the sample layer and the nature of the substrate surface. Unfortunately, direct absorption of radiation by the sample may lead to fragmentation and therefore loss of the ability to determine the molecular weight.

By dispersing the sample in a radiation-absorbing matrix [3,4], the chance of radiation damage is reduced considerably. Typically, a solution of a few picomoles of analyte is mixed with an excess (100-10,000-fold) of matrix molecules. A few microliters of the resulting solution is deposited on a mass spectrometry probe and allowed to dry before inserting the probe into the mass spectrometer. The matrix is chosen to isolate the analyte molecules from each other and vaporizes after absorbing laser light, leading to desorption and ionization of the analyte molecules. The mechanisms involved in MALDI and the associated matrix selection are still not fully understood. When matrices of highly similar structures were compared, large differences in MALDI efficiencies for the same analyte were obtained [5]. It is suggested that the matrix transfers its high vibrational energy obtained after radiation more readily to the crystal lattice than to the analyte molecules, resulting in the vaporization of the matrix molecules and transportation of the analyte molecules into the gas phase with only a small amount of internal energy [6].

The ions generated by MALDI are generally analyzed by use of TOF mass spectrometry. Although MALDI is a soft ionization technique, there are studies where it is believed that unimolecular decay along the TOF flight tube takes place [7-9]. Whereas small peptides produce structurally informative fragments arising from backbone cleavages, larger protein ions fragment by non-specific losses of small neutral groups.

For further information about MALDI, an impressive review article containing a large database of studies performed with the use of this technique [10] together with a more recent minireview by Stults [11] are recommended.

\section{Electrospray ionization (ESI)}

Electrospray is a soft ionization technique that is applied to generate multiply charged gas phase ions of large macromolecules under atmospheric conditions. The essential feature of ESI involves a continuous flow of a sample solution containing the analyte through a metal needle maintained at a high electric field of several kilovolts. Electric instabilities introduced at the needle tip lead to dispersion of the solution into a cloud of small charged droplets and subsequent liberation of ions from these droplets at atmospheric pressure. It is suggested by the Taylor-Cone theory that during the vaporization of the solvent molecules, the density of charge on the surface of the droplets increases to the surface tension (Rayleigh limit) [12,13]. If the density of charge increases beyond the surface tension, the droplets become unstable and explode into smaller droplets. This process continues until droplets are formed which only contain one analyte molecule. After vaporization of the final solvent molecules, multiply charged analyte ions are left. Another mechanism, the field desorption model, is proposed by Iribarne and Thomson [14,15]. In this model, vaporization of the solvent molecules leads to an accumulation of charge on the analyte ions. If this charge reaches a certain value, the analyte ions may desorb from the solvent molecules into the gas phase. 
Since the analyte ions generated by ESI are multiply charged, analysis of the obtained mass spectra must be done with great care. With conventional low-resolution mass spectrometers, determination of the molecular mass is accomplished by indirect and iterative computation. The FT-ICR technique on the other hand provides the necessary resolution to determine the molecular mass in a simple way. The charge state of an ion can be established by counting the number of ${ }^{13} \mathrm{C}$ isotopic peaks present in one mass unit. Eventually, the molecular mass can be calculated by multiplying the charge state by the apparent mass-to-charge ratio.

Since the analyte ions generated by ESI are multiply charged, molecules with masses up to several millions of daltons can be analyzed [2]. A second advantage of ESI is its ready compatibility with liquid chromatography and capillary electrophoresis since it is designed as a technique for flowing liquid solutions.

Further information about ESI can be found in the review article by Burlingame et al. [10].

\section{Fourier transform ion cyclotron resonance (FT-ICR)}

FT-ICR mass spectrometry has been introduced in 1974 by Comisarow and Marshall [16-18,3]. Ions can be generated in the FT-ICR cell from gas-phase sample molecules by electron ionization or may be injected into the FT-ICR cell from an external ion source. The technique is based on the principle that charged particles describe circular paths perpendicular to the direction of a uniform magnetic field and may be trapped for a variable period of time (ms to hours), whereby ions of interest may be selected by ejecting all other ions from the cell. This is done by applying radio frequency pulses to ions with certain $\mathrm{m} / \mathrm{z}$ ratios thereby increasing the kinetic energy of these ions and consequently the radius of their circular orbits to such values that they are ejected from the cell. After ejection of the unwanted ions it is possible to study ion/molecule reactions between the selected ion and molecules present in the cell by varying the time delay between the selection of the ion of interest and the start of the excitation pulse. This excitation pulse accelerates all the ions present in the cell to larger orbits. Packets of ions of a given $\mathrm{m} / \mathrm{z}$ value will now move coherently in phase in a larger circular orbit. The excited ions move up and down between the receiver plates creating ion image currents which decay with time as the coherent motion is destroyed by ion/molecule collisions. These decaying image currents, known as a transient time-domain signal, are then converted into a digital signal and stored in the computer. This sequence of events can be repeated for a chosen number of times to improve the signal-to-noise ratio. Finally, the summed digitized signal is then subjected to Fourier transformation to generate a frequency domain spectrum, which can easily be converted into a mass spectrum.

By repeating the procedure of ejection of unwanted ions, FT-ICR provides unique multiple MS capabilities. This special feature has been applied extensively for the study of complex ion/molecule reactions in the gas phase [19-21,4].

The FT-ICR technique can also be combined with gas- or liquid chromatography and capillary electrophoresis for analytical purposes. In a recent paper, liquid chromatography has been interfaced with FT-ICR for the analysis of aromatic hydrocarbons and aromatic compounds containing sulphur, nitrogen or oxygen in petroleum distillates and refinery streams. The ultra-high mass resolution provided by FT-ICR enabled the identification of their chemical formulas [22]. 


\section{Combination of MALDI or ESI with FT-ICR}

The energy spread and the temporal distribution of the initially generated ions upon MALDI make it difficult to trap and drive these ions into a coherent ion packet in an FT-ICR instrument [23]. This is the reason why until recently the application of MALDI/FT-ICR was limited to relatively low molecular weight compounds [24,25]. Several attempts have been made to solve the difficulties associated with the trapping and detection of large ions by FT-ICR. By the use of high trapping potentials and collisional cooling, singly charged ions derived from molecules with molecular weights up to $12 \mathrm{kDa}$ were detected [26]. Other efforts include the use of sugar as co-matrix [27,28] and other binary matrices [29] which also resulted in an improved mass measurement accuracy up to $15 \mathrm{kDa}$. It is thought that the use of a sugar as co-matrix minimizes metastable decay of the analyte ions. The sugar is supposed to absorb excess energy and pyrolyze at a lower temperature than the analyte, producing a momentary high pressure of small neutrals which can cool the desorbing analyte [30,31].

The performance of MALDI-FT-ICR with respect to MALDI-TOF MS and gel permeation chromatography (GPC) is illustrated by the analysis of an industrial polymer [32]. The GPC and TOF techniques give information about the apparent molecular mass distribution, while FT-ICR also yields information on the repeating units of the polymer. Furthermore, the MALDI-FT-ICR result was obtained by use of a single laser shot while the result acquired by the combination of MALDI with TOF MS was averaged over 50 laser shots.

Much attention has been given to the resolution of MALDI-FT-ICR mass spectra of bovine insulin and resolving powers larger than 10,000 for $\mathrm{m} / \mathrm{z} 5734$ have been reported [28,33-35]. Internal and external ionization of MALDI-FT-ICR have been discussed by Li and McIver, Jr. [33]. With internal ionization MALDI experiments, the ions expand directly away from the probe tip and enter the FT-ICR cell. In the external ionization method the MALDI source is more than $1 \mathrm{~m}$ away from the FT-ICR cell. It seems that internal ionization leads to frequency shifts, probably caused by space-charge effects. These space-charge effects result in reduced mass resolution, mass measurement accuracy and sensitivity [36,37]. However, external ionization has led to the reported mass resolution of 90,000 for the peak due to the protonated molecule of bovine insulin [35] which is significantly higher than reported values for internal ionization.

The MALDI-FT-ICR technique can also be used to obtain structural information of low molecular weight polymers. Polyethylene glycol and polyvinyl pyrrolidone polymers with an unknown end group elemental composition have been investigated in the mass range up to 5000 daltons with the determination of the end group within a deviation of less than one mass unit [38,39]. Marshall and co-workers derived structural information on phospolipids by combining MALDI with FT-ICR [40].

The second ionization method which combined with FT-ICR can provide accurate mass measurement is ESI. This technique produces intact multiply charged species which allows detection to take place at relatively low mass-to-charge ratios $(\mathrm{m} / \mathrm{z}<2000)$, a region in which the mass precision and resolution of FT-ICR are unique. However, for complex mixtures it is not as simple as it appears to determine the molecular masses. In order to obtain the necessary resolving power, it is crucial to select data acquisition parameters based on the predicted behaviour of the time domain signal for the efficient and accurate acquisition of mass spectra [41]. If this is done properly, a resolving power for bovine insulin of 700,000 can be achieved [42]. Beu et al. have been able to identify the $13+$ charge state of cytochrome $c$ from the $18+$ charge state of myoglobin in a broadband mode which requires a resolution of 106,000 for $\mathrm{m} / \mathrm{z} 942$ [43]. ESI combined with FT-ICR also enables analysis of trace impurities in drugs [44]. 
ESI coupled to FT-ICR can also be used for obtaining structural information on biomolecules. Primary structural information, derived from fragment ions after dissociation of the quasi-molecular ions, can be obtained by multiple MS measurements $[45,46]$. Tertiary structural information can be deduced from gas-phase hydrogen/deuterium exchange experiments to distinguish different conformations of proteins in the gas-phase. In this way, McLafferty and co-workers found three distinct gas-phase conformations of cytochrome $c$ whose reactivities were consistent with those of known solution-phase conformations [47]. More recent results from the group of McLafferty involve the combination of capillary electrophoresis with ESI and FT-ICR. Dissociation of molecular ions from $9 \times 10^{-18}$ mole of carbonic anhydrase ( $M=28,780$ daltons) gave nine sequence-specific fragment ions, thereby providing more information than required for the unique retrieval of this enzyme from the protein database [5].

\section{Conclusions}

The successful application of mass spectrometry to analyze biomolecules and polymers has led to an increased application of MALDI and ESI over the last years. The combination of these two soft ionization techniques with FT-ICR has many advantages over other mass spectrometric methods since the ultra-high resolution of FT-ICR can be used for obtaining accurate molecular masses of compounds with molecular weights larger than $10 \mathrm{kDa}$. Comparison of the results produced by MALDI and ESI indicates that each technique has its own advantages and limitations. The mass range achievable with use of ESI is considerably larger and has shown already to be up to one hundred million daltons. For analysis of compounds which are not readily multi- or de-protonated, such as non-polar polymers, MALDI is more suitable than ESI.

\section{References}

[1] M.A. Posthumus, P.G. Kistemaker and H.L. Meuzelaar, Anal. Chem. 50 (1978), 985.

[2] J.R. Cotter, Anal. Chem. 56 (1984), 485A.

[3] K. Tanaka, H. Waki, Y. Ido, S. Akita, S. Yoshida and T. Yoshida, Rapid Commun. Mass Spectrom. 2 (1988), 151.

[4] M. Karas and M. Hillenkamp, Anal. Chem. 60 (1988), 2299.

[5] R.C. Beavis, Org. Mass Spectrom. 27 (1992), 653.

[6] R.E. Johnson, Int. J. Mass Spectrom. Ion Processes 139 (1994), 25.

[7] B. Spengler, D. Kirch and R. Kaufmann, Rapid Commun. Mass Spectrom. 5 (1991), 198.

[8] P. Demirev, J.K. Olthoff, C. Fenselau and R.J. Cotter, Anal. Chem. 59 (1987), 1951.

[9] D.L. Bunker and F.-M. Wang, J. Am. Chem. Soc. 99 (1977), 7457.

[10] A.L. Burlingame, R.K. Boyd and S.J. Gaskell, Anal. Chem. 66 (1994), 634R.

[11] J.T. Stults, Curr. Opinion Struct. Biol. 5 (1995), 691.

[12] M. Dole, L.L. Mack, R.L. Hines, R.C. Mobley, L.D. Ferguson and M.B. Alice, J. Phys. Chem. 49 (1968), 2240.

[13] M.S. Wilm and M. Mann, Int. J. Mass Spectrom. Ion Processes 136 (1994), 167.

[14] B.A. Thomson and J.V. Iribarne, J. Chem. Phys. 71 (1979), 4451.

[15] J.V. Iribarne, P.J. Dziedzic and B.A. Thomson, Int. J. Mass Spectrom. Ion Phys. 50 (1983), 331

[16] M.B. Comisarow and A.G. Marshall, Chem. Phys. Lett. 25 (1974), 282.

[17] M.B. Comisarow and A.G. Marshall, Can. J. Chem. 52 (1974), 1997.

[18] M.B. Comisarow and A.G. Marshall, J. Mass Spectrom. 31 (1996), 581.

[19] N.M.M. Nibbering, Adv. Phys. Org. Chem. 24 (1988), 1.

[20] N.M.M. Nibbering, Acc. Chem. Res. 23 (1990), 279.

[21] N.M.M. Nibbering, Trends Anal. Chem. 13 (1994), 223.

[22] S. Guan, A.G. Marshall and S.E. Scheppele, Anal. Chem. 68 (1996), 46.

[23] R.C. Beavis and B.T. Chait, Chem. Phys. Lett. 181 (1991), 479. 
[24] R.L. Rettich and M.V. Buchanan, J. Am. Soc. Mass Spectrom. 2 (1991), 402.

[25] M.V. Buchanan and R.L. Rettich, Anal. Chem. 65 (1993), 245A.

[26] T. Solouki and D.H. Russell, Proc. Natl. Acad. Sci. USA 89 (1992), 5701.

[27] J.A. Castoro and C.L. Wilkins, Anal. Chem. 65 (1993), 2621.

[28] C. Koster, J.A. Castoro and C.L. Wilkins, J. Am. Chem. Soc. 114 (1992), 7572.

[29] T. Solouki, K.J. Gillig and D.H. Russell, Rapid Commun. Mass Spectrom. 8 (1994), 26.

[30] R.C. Beavis, J. Lindner, J. Grotemeyer and E.W. Schlag, Chem. Phys. Lett. 146 (1988), 310

[31] J.A. Castoro and C.L. Wilkins, Trends Anal. Chem. 13 (1994), 229.

[32] J.E. Campana, L.-S. Sheng, S.L. Shew and B.E. Winger, Trends Anal. Chem. 13 (1994), 239.

[33] Y. Li and R.T. McIver, Jr., Rapid Commun. Mass Spectrom. 8 (1994), 743.

[34] Y. Li, R.T. McIver, Jr., and R.L. Hunter, Anal. Chem. 66 (1994), 2077.

[35] R.T. McIver, Jr., Y. Li and R.L. Hunter, Int. J. Mass Spectrom. Ion Processes 132 (1994), L1.

[36] T. Solouki, K.J. Gillig and D.H. Russell, Anal. Chem. 66 (1994), 1583.

[37] S. Guan, M.C. Wahl and A.G. Marshall, Anal. Chem. 65 (1993), 3647.

[38] C.G. de Koster, M.C. Duursma, G.J. van Rooij, R.M.A. Heeren and J.J. Boon, Rapid Commun. Mass Spectrom. 9 (1995), 957.

[39] G.J. van Rooij, M.C. Duursma, R.M.A. Heeren, J.J. Boon and C.G. de Koster, J. Am. Soc. Mass Spectrom. 7 (1996), 449.

[40] J.A. Marto, F.M. White, S. Seldomridge and A.G. Marshall, Anal. Chem. 67 (1995), 3979.

[41] S.A. Hofstadler, J.E. Bruce, A.L. Rockwood, G.A. Anderson, B.E. Winger and R.D. Smith, Int. J. Mass Spectrom. Ion Processes 132 (1994), 109.

[42] B.E. Winger, S.A. Hofstadler, J.E. Bruce, H.R. Udseth and R.D. Smith, J. Am. Soc. Mass Spectrom. 4 (1993), 566.

[43] S.E. Beu, M.W. Senko, J.P. Quinn and F.W. McLafferty, J. Am. Soc. Mass Spectrom. 4 (1993), 190.

[44] N.J. Haskins, C. Eckers, A.J. Organ, M.F. Dunk and B.E. Winger, Rapid Commun. Mass Spectrom. 9 (1995), 1027.

[45] Y. Huang, L. Pasa-Tolic, S. Guan and A.G. Marshall, Anal. Chem. 66 (1994), 4385.

[46] F.W. McLafferty, Acc. Chem. Res. 27 (1994), 379.

[47] D. Suckau, Y. Shi, S.C. Beu, M.W. Senko, J.P. Quinn, F.M. Wampler, III, and F.W. McLafferty, Proc. Natl. Acad. Sci. USA 90 (1993), 790.

\section{References added in proof}

[48] R.D. Edmonson and D.H. Russell, J. Am. Soc. Mass Spectrom. 7 (1996), 995.

[49] R. Chen, X. Cheng, D.W. Mitchell, S.A. Hofstadler, Q. Wu, A.L. Rockwood, M.G. Sherman and R.D. Smith, Anal. Chem. 67 (1995), 1159.

[50] A.G. Marshall and P.B. Grosshans, Anal. Chem. 63 (1991), 215A.

[51] N.M.M. Nibbering, Recl. Trav. Chim. Pays-Bas 105 (1986), 245.

[52] G.A. Valaskovic, N.L. Kelleher and F.W. McLafferty, Science 273 (1996), 1199. 


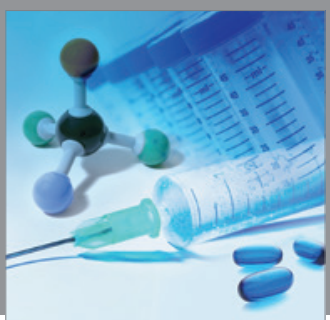

International Journal of

Medicinal Chemistry

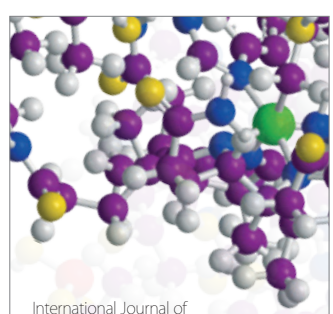

Carbohydrate Chemistry

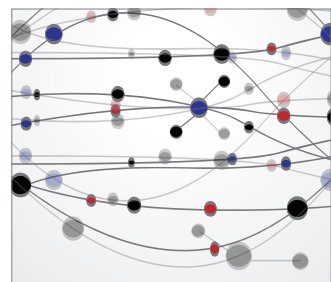

The Scientific World Journal
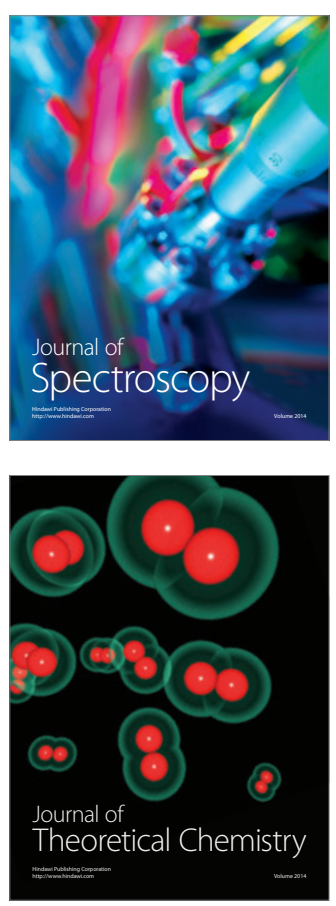
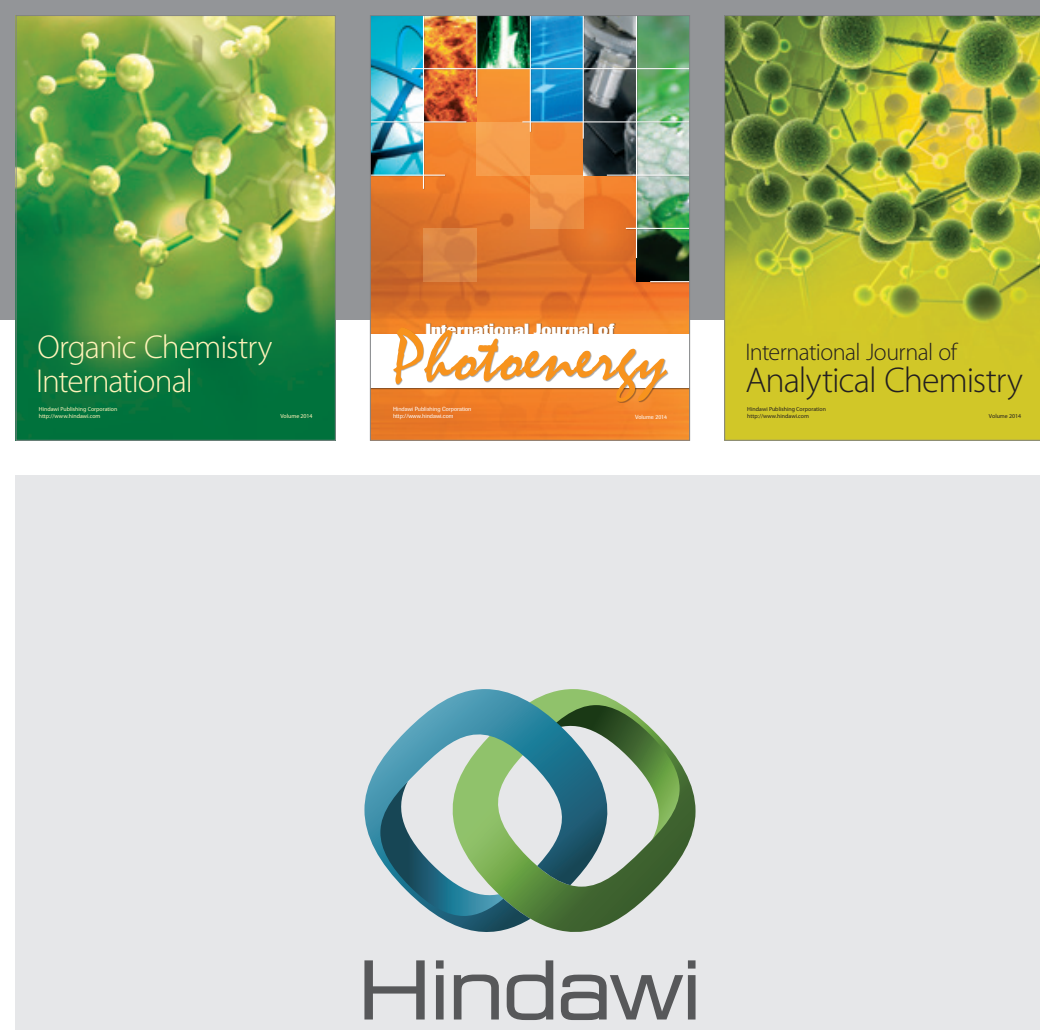

Submit your manuscripts at

http://www.hindawi.com
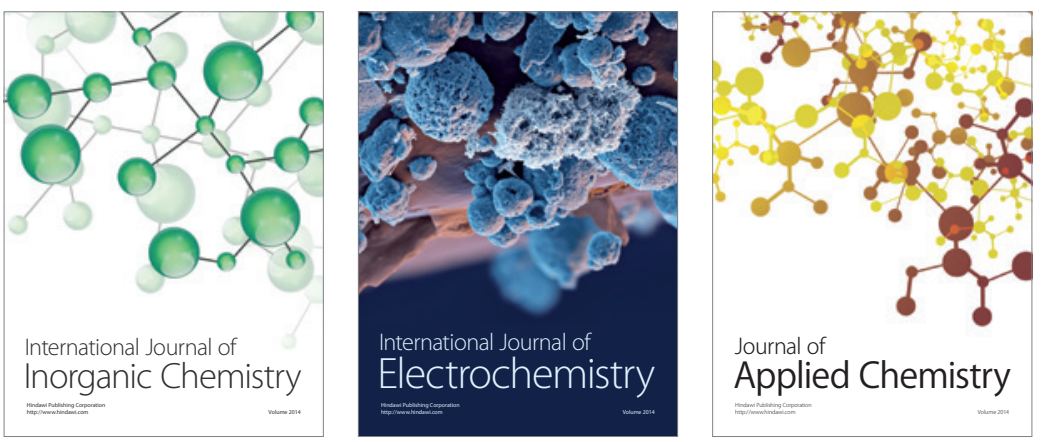

Journal of

Applied Chemistry
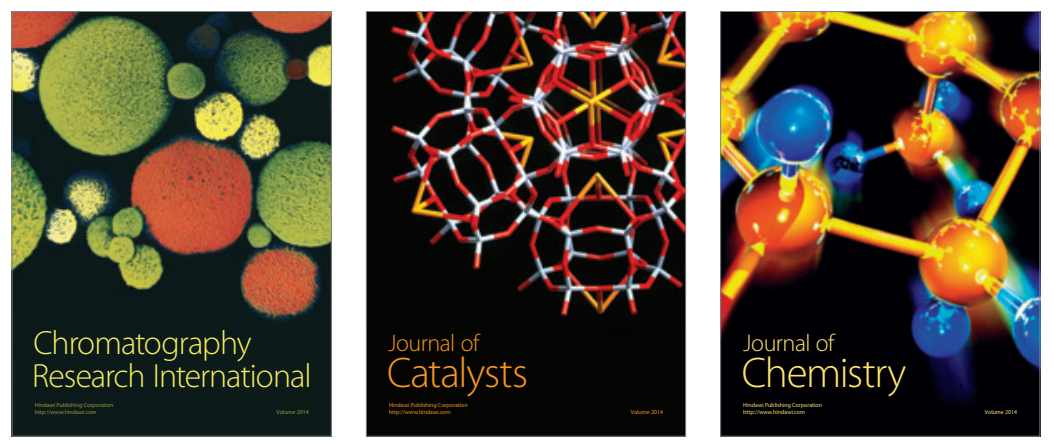
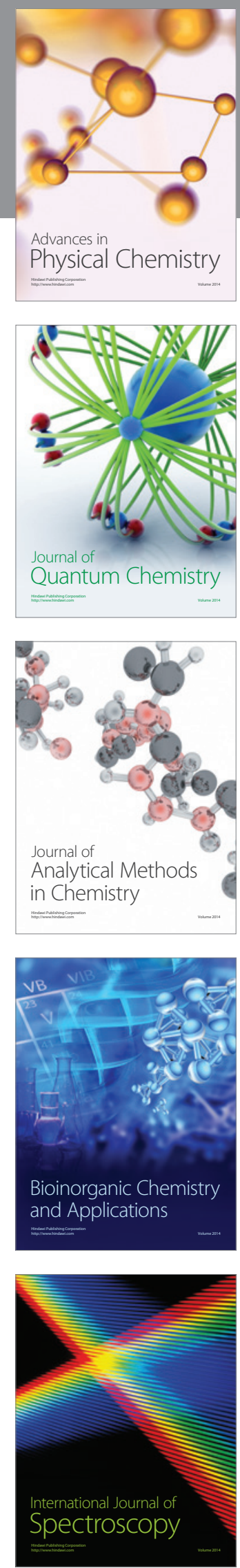